\title{
ASPECTOS FENOMENOLÓGICOS DO CONCEITO DE REDE: O ALEPH, UBIQÜIDADES*
}

\author{
Antônio Zumpano** \\ José Carlos Cavalheiro da Silveira*** \\ Marco Antônio de Oliveira*** \\ Maria Antonieta Pereira**
}

Resumo: $O$ artigo analisa o conceito de infinito na literatura de Jorge Luis Borges. Mostra como a literatura é capaz de tecer uma malba relacional criando situações para que conceitos oriundos de vários saberes possam ser apreendidos.

Todos sabemos do encanto de Borges por temas que envolvem o conceito de infinito e seus paradoxos. As preocupações filosóficas e científicas, não raramente, aparecem em seus textos como elemento estético. No conto "A Biblioteca de Babel", encontramos um exemplo disso: "como todos os homens da Biblioteca, viajei na minha juventude; peregrinei em busca de um livro, talvez do catálogo de catálogos; agora que meus olhos quase não podem decifrar oque escrevo, preparo-me para morrer, a poucas léguas do hexágono em que nasci" (BORGES, 1999:516). O catálogo de todos os catálogos é uma alusão ao paradoxo de Bertrand Russel que mostra a inconsistência da teoria dos conjuntos. Catálogo ab-

\footnotetext{
- Recebido para publicação em maio de 2003.

" Professores, respectivamente, do ICEX, da Faculdade de Medicina e da Faculdade de Letras da UFMG.
} 
soluto, referencial, mas ilusório, inútil, pois talvez terminamos bem próximos de onde começamos. Ainda nesse mesmo conto Borges vai se referir ao desdobramento do paradoxo de Russel, sob a forma dos teoremas de Gödel, que demonstram a impossibilidade de se demonstrar a verdade: “... o catálogo fiel da Biblioteca, milhares e milhares de catálogos falsos, a demonstração da falácia desses catálogos, a demonstração da falácia do catálogo verdadeiro,..." (519) . Em outro trecho do conto, encontramos uma maravilhosa ironia ao princípio de indução matemática que foi axiomatizado por Peano no final do século XIX (1889). Esse princípio lida com a essência (ousia) do infinito, tendo por objetivo tornar atual o infinito e transgredir o estabelecido por Aristóteles: a essência do infinito está em um processo que se pode levar adiante sem fim, que tem o seu ser unicamente na forma de possibilidade, ou seja, o infinito existe em potência, não em ato. Lemos em Borges,

Como localizar o venerado hexágono secreto que o hospedava? Alguém propôs um método regressivo: Para localizar o livro A, consultar previamente um livro $\mathrm{B}$, que indique o lugar de $\mathrm{A}$; para localizar o livro $\mathrm{B}$, consultar previamente um livro $\mathrm{C}$, e assim até o infinito... Em aventuras como essas, prodigalizei e consumi meus anos. Não me parece inverossímil que em alguma prateleira do universo haja um livro total... basta que um livro seja possível para que exista. (521)

Na última frase, escrita no conto como nota de pé de página, a ironia se sublima, visto que a matemática do século $\mathrm{XX}$ recusa qualquer conceito em potência, vive em um eterno subjuntivo, mas atual, em ato. Mais uma referência à matemática encontra-se em "A Biblioteca é uma esfera cujo centro cabal é qualquer hexágono, cuja circunferência é inacessível"(517). Trata-se da esfera de Pascal, mencionada no conto homônimo (12) e também em "O Aleph": uma esfera cujo centro está em toda parte e a circunferência em nenhuma. Borges chama-a de "metáfora geométrica" e a 
interpreta; seu sentido é claro na mente medieval: "Deus está em cada uma de suas criaturas, mas nenhuma $O$ limita" 6 . Ele cita ainda a passagem bíblica em que Salomão ora a Deus: "Eis que os céus, e até o céu dos céus, não te podem conter, quanto menos esta casa que eu edifiquei" (I Reis 8, 27). (Salomão, evidentemente, refere-se ao templo que ele tinha construído em Jerusalém.) Borges alega que, na época, a metáfora geométrica da esfera deve ter parecido uma nota explicativa, uma glosa, desta passagem. Em relação ao Renascimento, Borges declara que Giordano Bruno usou essa metáfora para explicar o espaço copernicano aos homens: "o universo é todo centro, ou o centro do universo está em toda parte e a circunferência em nenhuma"(14). Esta mesma esfera que liberta Bruno é um labirinto e um abismo para Pascal, que gostaria de adorar a Deus, mas Deus agora é menos real do que o espaço infinito, sem vozes, que o apavora. É o século XVII, barroco, buscando desesperadamente a certeza perdida com a ruptura renascentista. Assim, Borges explica que "talvez a história universal seja a história das várias entonações de algumas metáforas" (15) .

No conto "O Aleph" a esfera reaparece, estando relacionada de perto com o Aleph. Sendo uma extensão infinita, sem referência, seu centro está em toda parte porque cada parte é uma réplica homotética do todo, que por sua vez é réplica de um todo maior, indefinidamente. Essa característica de auto-semelhança homotética também aparece no conto "As Ruínas Circulares"(499) : o ser que sonha também é sonhado por outro ser, ele é o sonho do outro, mas também sonha um outro. Não há, portanto, uma referência global, é como se houvesse uma manutenção do aqui, um bic stans. Como isso se relaciona com o Aleph? O Aleph é um dos pontos do espaço que contém todos os pontos. Como ele também é um ponto, logo está também dentro dele, não como réplica homotética, mas como ele mesmo. A primeira é uma característica das estruturas chamadas de "fractais" e a outra é a característica principal do conjunto universo de Cantor. 
O próprio Borges, em entrevista, afirma que a idéia do Aleph é espelhada no conceito de eternidade dos teólogos: um instante no qual está contido todo o tempo. O Aleph, portanto, pode ser visto como uma eternidade do espaço.Tal eternidade seria a manutenção do presente, do agora, um nunc stans.

Na epígrafe do conto há referência ao Leviatã, de Thomas Hobbes. Contemporâneo de Francis Bacon, Descartes e Galileu, imbuído no espírito renascentista, Hobbes quer desconstruir o pensamento medieval, as certezas inúteis e descabidas, as explicações irracionais com apelo ao sobrenatural. Assim como os outros de sua época, ele renuncia ao conhecimento da essência da natureza, da ousia da natureza. Nesse sentido, o aforismo de Francis Bacon "pela renúncia venceremos a natureza", por mais paradoxal que seja, revela que o processo para dominar a natureza, obter previsibilidade, controlar suas forças, arrancar seus segredos, envolve a renúncia ao conhecimento de sua essência. Essa atitude é fundamental para Galileu que se afastou da tradição aristotélicomedieval renunciando a investigar as causas do movimento dos corpos para se limitar à descrição deste. Galileu faz uma análise quantitativa do movimento, examina como as grandezas espaço e tempo se relacionam, e em vez de perguntar porque ou para que se movem, pergunta como se movem. De certa forma desconsiderase o significante, o que se quer é um significado, uma interpretação, uma conjectura que seja conveniente, certamente intencional, ou seja, capaz de doar significado. Vejamos o que Hobbes diz na referência indicada por Borges. No capítulo 46 de Leviatãa, lemos:

E em particular, da essência do homem que (dizem eles) é sua alma, afirmam que ela está toda em seu dedo mindinho e toda em qualquer outra parte (por menor que seja) de seu corpo, e contudo não há mais alma em todo o corpo do que em qualquer uma dessas partes. Pode alguém supor que se 
serve a Deus com tais absurdos? E contudo tudo isso é necessário para a crença, para aqueles que acreditam na existência de uma alma incorpórea separada do corpo. (HOBBES, 1974:394)

E ainda:

Quanto ao significado de eternidade, não querem que seja uma infindável sucessão de tempo, pois nesse caso não seriam capazes de apresentar uma razão a cerca de como é que a vontade de Deus e a preordenação das coisas que estão para vir não deveriam vir antes de sua presciência delas, tal como a causa eficiente antes do efeito, ou o agente antes da ação; nem a cerca de muitas outras atrevidas opiniões a respeito da natureza incompreensível de Deus. Mas dir-nos-ão que a eternidade é a manutenção do presente, o nunc stans (como as escolas lhe chamam) que nem eles nem ninguém compreende, tal como não compreenderiam um bic stans para uma infinita grandeza de espaço"(ibdem).

O Aleph é, portanto, o bic stans, o sempre aqui, a manutenção do aqui.

Vemos a dificuldade de colocar o conceito de infinito dentro dos parâmetros racionais. É algo que escapa ao logos e ao ratio: à contagem, ao cálculo, à mensuração. $O$ narrador declara depois de ver o Aleph: "É possível que os deuses não me negassem o achado de uma imagem equivalente (ao Aleph), mas esse relato ficaria contaminado de literatura, de falsidade. Mesmo porque o problema central é insolúvel: a enumeração, sequer parcial, de um conjunto infinito" (BORGES, 1999:695).

Por esse motivo, Aristóteles declara a natureza potencial do infinito. No século XVI, Galileu, Newton e Leibniz sabiam do problema que se cria ao admitir o infinito atual, qual seja, a negação do axioma fundamental de Euclides, de que o todo é maior que a parte. Galileu tenta pensar em um infinito atual e se depara com o 
seguinte paradoxo: existem tantos números quadrados como há números, tantos números pares quantos os números. Em outras palavras, o paradoxo de Galileu afirma que o todo nem sempre é maior que a parte, contrariando assim o axioma fundamental de Euclides. Toda a ciência, até a segunda metade do século XIX, prende-se ao conceito de infinito em potência, de Aristóteles. As teorias da física e da matemática tornam-se mais sofisticadas devido à necessidade de explicar e controlar fenômenos que envolvem dinâmicas cada vez mais complexas. O conceito aristotélico de infinito torna-se então um empecilho para a fundamentação dessas teorias e, no final do século XVIII, o enciclopedista D'Alembert desabafa: precisamos rever a matemática, não sabemos: onde estamos pisando nem o que estamos concluindo, atropelamos o sistema dedutivo grego. O impasse estava formado: de um lado, $o$ paradoxo de Galileu e, de outro, a falta de fundamento.

Só em 1872 o matemático alemão Georg Cantor e três outros cientistas iniciam o trabalho de fundamentação da matemática. Cantor constrói os números irracionais e resolve o problema da incomensurabilidade, descoberto pelos pitagóricos: a insuficiência do sistema numérico para medir todos os segmentos. Ou seja, Cantor recupera a racionalidade das grandezas geométricas comprimento, área e volume - perdida na época de Pitágoras, 500 a.C. Mas não é disso que trataremos aqui. Vamos contemplar um outro feito de Georg Cantor, muito mais importante que esse, qual seja, a criação da teoria dos conjuntos infinitos: a Mengenlehre, proposta na virada do século dezenove para o século vinte. Para isso, foi preciso transgredir a lei, romper com o conceito aristotélico de infinito potencial, reforçar a renúncia ao conhecimento da essência da natureza e criar as infinitudes atuais, o conjunto infinito atual. Cantor resolve o paradoxo de Galileu de maneira sutil: simplesmente nega o paradoxo e afirma que a negação do axioma fundamental de Euclides é exatamente a característica própria, ontológica, dos conjuntos infinitos atuais. Usando uma notação 
audaciosa para representar o conjunto dos números ele abre chave, escreve os três primeiros números naturais - um, dois, três - e coloca reticências para indicar a seqüência infinita, fechando, em seguida, a chave, para indicar que atualizou o infinito:

$$
\{1,2,3 \ldots\} \text {. }
$$

Essa é a notação que todos usamos na escola básica para representar os conjuntos. Portanto, para conjuntos infinitos não vale o axioma fundamental de Euclides, ou seja, sempre existe uma parte que não é menor que o todo.

Trabalhando em sua teoria, Cantor descobre algo espantoso sobre o infinito, agora atualizado. Descobre que existem infinitos maiores e infinitos menores, e que eles se ordenam de maneira crescente e dão continuidade à seqüência dos números naturais. $\mathrm{Na}$ verdade, a atualização do infinito faz surgir, epifanicamente, outra espécie de número, diferente dos naturais e com propriedades aritméticas singulares. Cantor contempla, perplexo, essa epifania e chama esses números de transfinitos. Além disso, ele usa a letra hebraica à (Aleph) para designar a seqüência crescente dos números transfinitos: $\grave{a}_{0}\left(\right.$ aleph $\left._{0}\right), \grave{a ̀}_{1}\left(\right.$ aleph $\left._{1}\right), \grave{a}_{2}\left(\right.$ aleph $\left._{2}\right) \ldots$. Os alephs são, assim, a continuação dos números naturais: podemos escrever $1,2,3, \ldots, \grave{a}_{0} \grave{a}_{1}, \grave{a}_{2} \ldots\left(\right.$ aleph $_{0}$, aleph $_{1}$, aleph $\left._{2}, \ldots\right)$. Existem, então, infinitos tamanhos de infinitos que são os números cardinais: infinitos cardinais finitos e infinitos cardinais infinitos, os alephs.

A teoria dos conjuntos é considerada o maior feito na história da matemática. Ela fundamenta todos os conteúdos matemáticos e várias teorias da física, além de ter dado início ao movimento estruturalista da matemática, permitindo-nos formar o conjunto de todos os conjuntos, o "conjunto universo" que mencionamos antes. Com a reconstrução da matemática, tendo por alicerce a teoria dos conjuntos, o conceito de ponto geométrico é também alterado, o ponto passa a ser um elemento do conjunto 
estruturante. Este, por sua vez, é o espaço que contém os pontos ou que é formado pelos pontos. Logo, para efeito geral, podemos chamar de ponto os elementos dos conjuntos - quer dizer, temos o conjunto, e os objetos que o formam são seus pontos, seus elementos. Se pensarmos no conjunto universo, concluímos o seguinte: seus elementos são conjuntos, qualquer conjunto, mas ele mesmo é um conjunto, portanto, ele é um elemento dele mesmo, um dos pontos que contém todos os outros pontos. O Aleph é este conjunto universo, os vários alephs são reproduções dele próprio, ele dentro dele mesmo infinitas vezes. Qual será falso? Qual será verdadeiro? São todos iguais, são um só. São um tipo de infinitas trindades agostinianas talvez.

Um problema que surge com a formação de conjuntos é o da anterioridade: primeiro temos os objetos, depois formamos o conjunto deles, ou seja, os elementos precedem o conjunto. Mas, no caso do conjunto universo, qual é o primeiro? O conjunto ou os seus elementos, já que ele é elemento dele mesmo?

O conceito de cardinalidade de Cantor generaliza o conceito de número: a correspondência enumeradora finita de Aristóteles (não só de Aristóteles, mas de qualquer pessoa que saiba contar) é substituída por uma correspondência biunívoca entre conjuntos. No conto "O tempo circular", Borges dá o seguinte exemplo, retirado de Bertrand Russel, quando discute a hipótese de que a história seja cíclica: "formemos o conjunto de todas as circunstâncias contemporâneas de uma circunstância determinada; em certos casos, todo conjunto precede a si mesmo" (435).

É impressionante a compreensão de Borges das idéias de Cantor, em seu caráter singular e simples, como quase todas as idéias belas. No conto "A Doutrina dos Ciclos", Borges descreve maravilhosamente um novo modo de contar:

Essa verossímil contestação de Friedrich Zaratustra me faz recorrer a Georg Cantor e a sua heróica teoria dos conjuntos. 
Cantor destrói o fundamento da tese de Nietzsche. Afirma a perfeita infinidade do número de pontos do universo, e até de um metro de universo, ou de uma fração desse metro. A operação de contar não é para ele outra coisa senão comparar duas séries. Por exemplo, se os primogênitos de todas as casas do Egito foram mortos pelo Anjo, salvo os que moravam em casas com um sinal vermelho na porta, é evidente que se salvaram tantos quantos sinais vermelhos havia, sem que isso importe enumerar quantos foram. Aqui a quantidade é indefinida; há outros agrupamentos em que é infinita. $O$ conjunto dos números naturais é infinito, mas é possível demonstrar que os ímpares são tantos quantos pares. Ao 1 corresponde o 2 . Ao 3 corresponde o 4 . Ao 5 corresponde o 6 , etc. A prova é tão irrepreensível quanto fútil mas não difere da seguinte, de que há tantos múltiplos de três mil e dezoito como há números - sem excluir destes o três mil e dezoito e seus múltiplos. Ao 1 corresponde o 3018. Ao 2 corresponde o 6036. Ao 3 corresponde o 9054. Ao 4 corresponde o 12072, etc.. Cabe afirmar o mesmo de suas potências, por mais que estas se ratifiquem à medida que progredimos. Ao 1 corresponde o 3018. Ao 2 corresponde o $3018^{2}$, ou seja, 9108324. Ao 3, etc. (426).

Esse último exemplo, o das potências, é o paradoxo de Galileu que Cantor transformou em propriedade fundamental do infinito atual.

Nesse mesmo conto, Borges prossegue sua aula:

Uma genial aceitação desses fatos inspirou a fórmula de que uma coleção infinita - por exemplo, a série natural de números inteiros - é uma coleção cujos elementos podem desdobrar-se, por sua vez, em séries infinitas. (Ou melhor, para eludir qualquer ambigüidade: conjunto infinito é aquele conjunto que pode equivaler a um de seus conjuntos parciais.) A parte, nessas elevadas latitudes da numeração, não é menos abundante que o todo: a quantidade precisa de 
pontos que há no universo é a que existe em um metro, ou em um decímetro, ou na mais profunda trajetória estelar. A série dos números naturais está bem ordenada: quer dizer, os termos que a formam são consecutivos; o 28 precede o 29 e segue o 27. A série dos pontos do espaço (ou dos instantes do tempo) não é assim ordenável; nenhum número tem sucessor ou predecessor imediato. É como a série dos fracionados segundo a magnitude. Que fração enumeraremos depois de $1 / 2$ ? Não 51/100, porque $101 / 200$ está mais próxima; não $101 / 200$ porque mais próxima é 201/400; não 201/400 porque mais próxima... O mesmo acontece com os pontos, segundo Georg Cantor. Podemos sempre intercalar mais outros em número infinito. Contudo, devemos procurar não conceber grandezas decrescentes. Cada ponto "já" é o final de uma infinita subdivisão. (427)

Borges coloca-nos em um labirinto com infinitos minotauros e não nos fornece nenhum fio de Ariadne. Talvez ele compartilhe da idéia de Francis Bacon, de renúncia à essência, considerando a interpretação como o único modo possível de conhecimento. $\mathrm{O}$ mundo, quem sabe, é estruturável, mas nunca definitivamente estruturado. Umberto Eco também afirma algo sobre a existência de uma rede, ou melhor, de rizomas, como querem Deleuze e Guattari. Um caule feito de modo que cada caminho possa ligar-se com qualquer outro. Não tem centro, não tem periferia, não tem saída, porque é potencialmente infinito. O espaço da interpretação, da conjectura, é um espaço de rizoma.

Resumen: El artículo analiza el concepto del infinito en la literatura de Jorge Luis Borges. Demuestra como la literatura es capaz de tejer una malla relacional creando situaciones para que conceptos venidos de varios saberes puedan ser aprebendidos. 


\section{Bibliografia}

BORGES, Jorge Luis. Obras Completas I. São Paulo: Editora Globo, 1999. . Obras Completas II. São Paulo: Editora Globo, 1999.

FALCONER, Kenneth. Fractal geometry - mathematical foundations and applications. New York: John Wilwy \& Sons, 1990.

HOBBES, Thomas. Leviatã $N$, 46; coleção Os Pensadores. São Paulo: Editora Abril Cultural, 1974.

KITCHER, Philip. The Nature of Mathematical Knowledge. New York: Oxford University Preas, 1984.

LÉVY, Pierre. As tecnologias da inteligência. Trad. C. L. Da Costa. Rio de Janeiro: Ed.34, 1993.

TAKENTI, Gaisi, ZARING, Wilson M. Axiomatic Set Theory. New york: Springer - Verlag, 1973.

ZUMPANO, Antônio. Os limites da matemática clássica. Ciência Hoje - Revista de divulgação científica da SBPC. V. 29. n.171, mai. 2001. p.77-79. 